\title{
Erysipelothrix rhusiopathiae. II. Enzyme immunoassay of sera from wild and captive marine mammals
}

\author{
Lynn D. Suer ${ }^{1}$, Neylan A. Vedros ${ }^{1}$, J. Pete Schroeder ${ }^{2}$, J. Lawrence Dunn ${ }^{3}$ \\ ${ }^{1}$ University of California, Berkeley, California 94720, USA \\ ${ }^{2}$ Naval Ocean Systems Center, Hawaii Lab., PO Box 997, Kailua, Hawaii 96734, USA \\ ${ }^{3}$ Mystic Marinelife Aquarium, Mystic, Connecticut 06335, USA
}

\begin{abstract}
An enzyme immunoassay (EIA) utilizing a lithium chloride sodium acetate extract of marine mammal isolates of the bacterium. Erysipelothrix ruhsiopathiae was developed to detect immune IgG in sera from marine mammals. Antibody levels were lower in 51 wild dolphins Tursiops truncatus compared with 11 captive, vaccinated dolphins $T$ truncatus and 11 captive, vaccinated false killer whales Pseudorca crassidens. Northern fur seal pups Callorhinus ursinus and stranded harbor seal pups Phoca vitulina richardsi had no significant antibodies to E. rhusiopathiae whereas $13 \%$ of 1-to 2-yr-old wild northern fur seals, $46 \%$ adult wild northern fur seals, $13 \%$ wild Hawaiian monk seal pups Monachus schauinslandi, $64 \%$ stranded adult California sea lions Zalophus californianus, $50 \%$ captive adult California sea lions, $55 \%$ captive adult harbor seals, $85 \%$ captive adult northern fur seals, $25 \%$ captive adult northern elephant seals Mirounga angustirostris and $38 \%$ captive adult grey seals Halichoerus grypus all had significant antibody levels.
\end{abstract}

\section{INTRODUCTION}

Erysipelas, caused by the bacterium Erysipelothrix rhusiopathiae, is considered to be one of the most serious diseases of captive cetaceans (Medway 1980) but of minor importance in captive pinnipeds (Sweeney 1978). Little is known of the distribution and importance of erysipelas in wild cetaceans or pinnipeds. The microorganisms are ubiquitous in nature and have been isolated from a variety of mammals and fowl (Bruner \& Gillespie 1973), the soil and manure of swine pens (Wood \& Packer 1972) and the slime of fish (Klauder 1938). Although the most likely antigenic challenge to marine mammals by E. rhusiopathiae is via their food source, there is as yet no clear evidence that E. rhusiopathiae 'infection' of fish in their natural environment occurs (Shewan 1971) or that the microorganisms are present in fresh-caught fish (Proctor \& Richardson 1954).

The purpose of the present study was to determine the exposure of wild and captive cetaceans and pinnipeds to Erysipelothrix rhusiopathiae by evaluating the level of antibodies to E. rhusiopathiae antigens present in their sera.

\section{MATERIALS AND METHODS}

Microorganisms. Erysipelothrix rhusiopathiae (Serotype partial 2) was isolated from the tooth/gum margin of an adult northern fur seal Callorhinus ursinus (NFS) as described in the companion article (Suer \& Vedros 1988). The bacteria Listeria monocytogenes and Corynebacterium xerosis were from the Biomedical and Environmental Health Sciences Department collection. All isolates were maintained in lyophile form at $4{ }^{\circ} \mathrm{C}$ until used.

IgG isolation. Serum from one wild bottlenose dolphin Tursiops truncatus and one adult NFS was run through a DEAE Affi Gel Blue (Biorad, Richmond, CA, USA) column $(1.5 \times 30 \mathrm{~cm})$. The IgG was eluted in buffer (0.02 M Tris- $\mathrm{HCl}, 0.028 \mathrm{M} \mathrm{NaCl}, \mathrm{pH} 7.3)$. Purity of the IgG was determined by immunoelectrophoresis using rabbit anti-whole serum of either dolphin or NFS.

Rabbit antisera. Rabbit anti-IgG was produced by subcutaneous (s.c.) injection of $1.0 \mathrm{mg} \operatorname{lgG}$ mixed in equal volume of Complete Freund's Adjuvant (Difco Co, Detroit, MI, USA) followed by a booster 3 wk later of $1.0 \mathrm{mg} \mathrm{IgG} \mathrm{in} \mathrm{Incomplete} \mathrm{Adjuvant} \mathrm{(s.c.).} \mathrm{The} \mathrm{rabbits}$ were bled $7 \mathrm{~d}$ later and serum stored at $-20^{\circ} \mathrm{C}$. 
Source of animal sera. Blood was collected from 269 cetaceans and pinnipeds (Table 1). After separation, the serum was stored at $-20^{\circ} \mathrm{C}$ until needed.

Serum absorption. The cells from a $48 \mathrm{~h}$ broth culture of Erysipelothrix rhusiopathiae, Corynebacterium xerosis, and Listeria monocytogenes were collected by centrifugation and adjusted to a concentration of $10^{8}$ bacteria $\mathrm{ml}^{-1}$. One $\mathrm{ml}$ of the suspended cells were pelleted in each of 6 conical centrifuge tubes and $1 \mathrm{ml}$ serum each of 5 dolphins Tursiops truncatus and 1 false killer whale Pseudorca crassidens added, vortexed vigorously, and incubated at $37^{\circ} \mathrm{C}$ for $2 \mathrm{~h}$ and $3{ }^{\circ} \mathrm{C}$ for $2 \mathrm{~d}$ with occasional shaking. The cells were removed by centrifugation and serum stored at $-20^{\circ} \mathrm{C}$ until used.

Chemical analysis. Protein concentration was determined as described by Lowry et al. (1951) and carbohydrates as described by Dubois et al. (1956). Standards consisted of Bovine Globulin (Biorad, Richmond, CA, USA) for the protein determinations and glucose (Fisher Scientific Co., Fairlawn, NJ, USA) for the carbohydrate determinations.

Enzyme immunoassay. Erusipelothrix rhusiopathiae (Serotypes partial 2, 5, 6, and 21) antigens were prepared from a $48 \mathrm{~h}$ growth in Nutrient Broth (Difco Co.) containing $2 \%$ newborn calf serum. The cells were collected by centrifugation $(10000 \times g, 20 \mathrm{~min})$, washed 3 times with Phosphate-Buffered Saline (PBS, $\mathrm{pH} \mathrm{7.4)}$ and extracted with $0.2 \mathrm{M}$ lithium chloride $0.1 \mathrm{M}$ sodium acetate (pH 5.8) as described by Frasch (1979). The average yield of protein was $49.5 \mu \mathrm{g} \mathrm{l}^{-1}$ culture. The antigen was dialyzed for $24 \mathrm{~h}$ against the enzyme immunoassay (EIA) antigen-coating bicarbonate buffer (pH 9.6). The average carbohydrate after dialysis of 5 lots was $16 \mu \mathrm{g} \mathrm{l}^{-1}$ culture. The optimum antigen con- centration $\left(200 \mu \mathrm{g} \mathrm{ml} \mathrm{ml}^{-1}\right.$ protein) was determined by block titration against 3 commercial equine anti $E$. rhisiopathiae sera (BioCeutic Lab., St Joseph, MO. USA, Lot \# 100-897; Colorado Serum Co., Denver, CO, USA, Lots \#724 and 740). The uninoculated serum served as the antigen control.

The optimum serum dilution (1:1000) was determined by block titration of the sera of selected dolphins with known vaccination histories as positive controls (dolphin No. TT 491) and in a similar manner a negative serum control was chosen (dolphin No. TG 623). A positive and negative serum control were also chosen for pinnipeds and all serum controls were included in every test.

The optimum dilution of rabbit anti-dolphin IgG, rabbit anti-NFS IgG, and goat anti-rabbit IgG (H \& L chains) horseradish peroxidase conjugate (Zymed Labs., San Francisco, CA, USA, Lot \# 024F8860) were

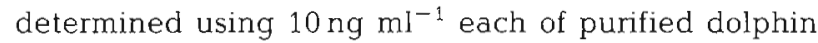
or NFS IgG.

The indirect EIA was conducted in microtiter plates (Immunolon II, Dynated, Denver, CO, USA) essentially as described by Voller et al. (1981). The antigen was fixed overnight at $4{ }^{\circ} \mathrm{C}$, then washed 3 times with PBS containing $0.05 \%$ Tween 20 (PBS-T). The test sera were diluted in PBS-T containing $0.5 \%$ bovine serum albumin Fraction V (Sci. Protein Labs,, Waunakee, WI, USA, Lot \# 10410111) and allowed to stand at room temperature for $1 \mathrm{~h}$ before adding to the wells $(200 \mu \mathrm{l})$. After $1 \mathrm{~h}$ at room temperature the plates were washed 3 times with PBS-T, the rabbit anti-dolphin or NFS IgG diluted in PBS- $T$ added, incubated for $1 \mathrm{~h}$ at room temperature, washed 3 times with PBS-T, followed by addition of the conjugate with similar room tempera-

Table 1. Source of sera

\begin{tabular}{|c|c|c|}
\hline Animals & Number in study & Comments \\
\hline \multicolumn{3}{|l|}{ Cetaceans } \\
\hline \multicolumn{3}{|l|}{ Dolphins } \\
\hline Wild & 51 & 18 newly captured in Gulf of Mexico; 33 off the west coast of Florida \\
\hline Captive & 11 & Vaccinated 2 to 5 times over a $10 \mathrm{yr}$ period \\
\hline False killer whales & 11 & Before and 6 wk after vaccination \\
\hline \multicolumn{3}{|l|}{ Pinnipeds } \\
\hline Pup NFS & 23 & Northern fur seals (NFS) on the Pribilof Islands, Alaska \\
\hline 1 - to 2 -yr-old NFS & 15 & Tagged seals on San Miguel Island, Californiã \\
\hline Adult NFS & 15 & 2- to 4-yr-olds, Pribilof Islands, Alaska \\
\hline Hawaiian monk seal pups & 8 & Windward Islands, Hawaii \\
\hline \multicolumn{3}{|l|}{ Stranded } \\
\hline California sea lions (CSL) & 39 & 22 bled after being fed fish; 17 bled before being fed fish \\
\hline Harbor seals (HS) & 29 & 1- to $10-d$-old pups \\
\hline Captive & 57 & 5 species in captivity for 6 mo to $10 \mathrm{yr}$ \\
\hline
\end{tabular}


ture incubation and washes. The substrate used was ophenylenediamine dihydrochloride (Sigma, Lot \# 54F5003), stopped after 30 min in the dark with $5 \mathrm{~N}$ sulfuric acid $(50 \mu l)$. The color development was determined at $492 \mathrm{~nm}$ in a Titertek Multiscan MCC 8-channel photometer (Flow Labs., Inglewood, CA, USA). No peripheral wells were used in any tests.

Quality control of the EIA was established by conducting 24 replicates of the positive reference sera on 7 different days to obtain an overall mean value as a standard of reproducibility. Tests were repeated when the mean adsorbance (optical density; OD) of the reference serum differed by more than 2 standard deviations from the mean value (maximum variation of $24 \%$ between plates and runs). Test serum values were multiplied by a normalizing factor, to minimize interassay variability, determined from the following ratio: Normalizing factor $=\frac{\text { Overall mean of pos. ref. serum }}{\text { Plate mean of pos. ref. serum }}$

In addition to primary and secondary antibody controls in each test, antigen controls consisted of uninoculated culture medium with protein concentration equivalent to the test antigen. The average adsorbence value of the antigen control was subtracted from the average adsorbence value of the test serum and the final value normalized.

Statistical analysis. To determine the cut-off point between positive and negative sera, discriminant analysis using 1 variable was accomplished using the Statistic Package for Social Services, 10th edn, as described by Kramer et al. (1983). The analysis was based on the final normalized test serum values of 2 populations: wild versus captive cetaceans and wild versus captive pinnipeds. Independent serum samples were used to construct and test the discriminant analysis.

Significant differences were determined by the student $t$-test at a $p$ value of 0.05 .

Polyacrylamide gel electrophoresis (SDS-PAGE). Ten $\%$ acrylamide gels $(12 \times 16.5 \mathrm{~cm})$ were prepared as described by Mishell \& Shiigi (1980). The antigens of the various serotypes $(40$ to $50 \mu \mathrm{g}$ ) and molecular weight markers (Sigma) were pre-heated $\left(100^{\circ} \mathrm{C}, 90 \mathrm{~s}\right)$ in twice-concentrated SDS containing 2-mercaptoethanol for gel loading. The separation was run for $9 \mathrm{~h}$ at $20 \mathrm{~mA}$ and gels stained overnight with Coomassie brilliant blue.

\section{RESULTS}

\section{EIA antigen}

The electrophoretic pattern of the antigens extracted from Serotypes 2, partial 2, 5, 6, and 21 for use in the
EIA are shown in Fig. 1. The 3 major bands were the same for all serotypes (Lanes $1,2,4,5,6)$ which consisted of molecular weights of approximately 62000 . 54000 , and 29000 daltons in descending order of intensity. Similar protein bands were not noted in extracts of Corynebacterium xerosis (Fig. 1, Lane 8) and Listeria monocytogenes (data not shown).

The specificity of the EIA antigen was determined by cross-adsorption of the positive sera of selected animals with the homologous microorganism and Corynebacterium xerosis and Listeria momocytogenes. The results in Table 2 indicate that with a single adsorption procedure some cross-reaction remained with $C$. xerosis and less with $L$. monocytogenes. After adsorption with the homologous Erysipelothrix rhusiopathiae the EIA mean value of all 6 animals was significantly lower than the mean value for $C$. xerosis or L. monocytogenes adsorption $(p<0.01)$.

\section{Pinnipeds}

Wild. The EIA values (Fig. 2) for NFS pups were negative (cut-off point $O D=0.187$ ). Positive were 2 of 151 - to 2-yr-old NFS on San Miguel Island (13\%), 9 of 15 adult NFS (46\%) and only 1 of 8 Hawaiian monk seal Monachus schauinslandi (MS) pups (13\%).

Stranded. The feeding of stranded animals with fish handled by humans for short periods of time prior to bleeding did not affect the results. The EIA values (Fig. 3) of 39 California sea lions Zalophus californianus (CSL) and 29 harbor seal Phoca vetulina richardsi (HS) pups fed fish 1 to $2 \mathrm{~d}$ after stranding and before being bled showed only a slightly higher percentage of positives (68\%) than the 17 CSL bled before being fed fish $(59 \%)$. The differences were not significant $(p>0.05)$. All of the 29 harbor seal pups ( 1 to $10 \mathrm{~d}$ old) were negative for antibodies to Erysipelothrix rhusiopathiae although all were being tube-fed fish formula at the time of bleeding.

Captive. The EIA values for a variety of captive pinnipeds are shown in Fig. 4. The percentage of positive sera for antibodies to Erysipelothrix rhusiopathiae was highest for NFS (85\%), followed by HS (55\%), CSL (50\%), grey seals Halichoerus grypus (38\%), and northern elephant seals Mirounga angestirostris (ES) $(25 \%)$. The only significant differences in the antibody responses were between the CSL and either NFS or HS $(\mathrm{p}<0.05)$ and between the NFS and the grey seals $(p<0.01)$ or $\operatorname{ES}(p<0.05)$.

\section{Cetaceans}

Wild. The EIA values for 2 groups of dolphins are shown in Fig. 5. Twelve \% of the specimens that were 


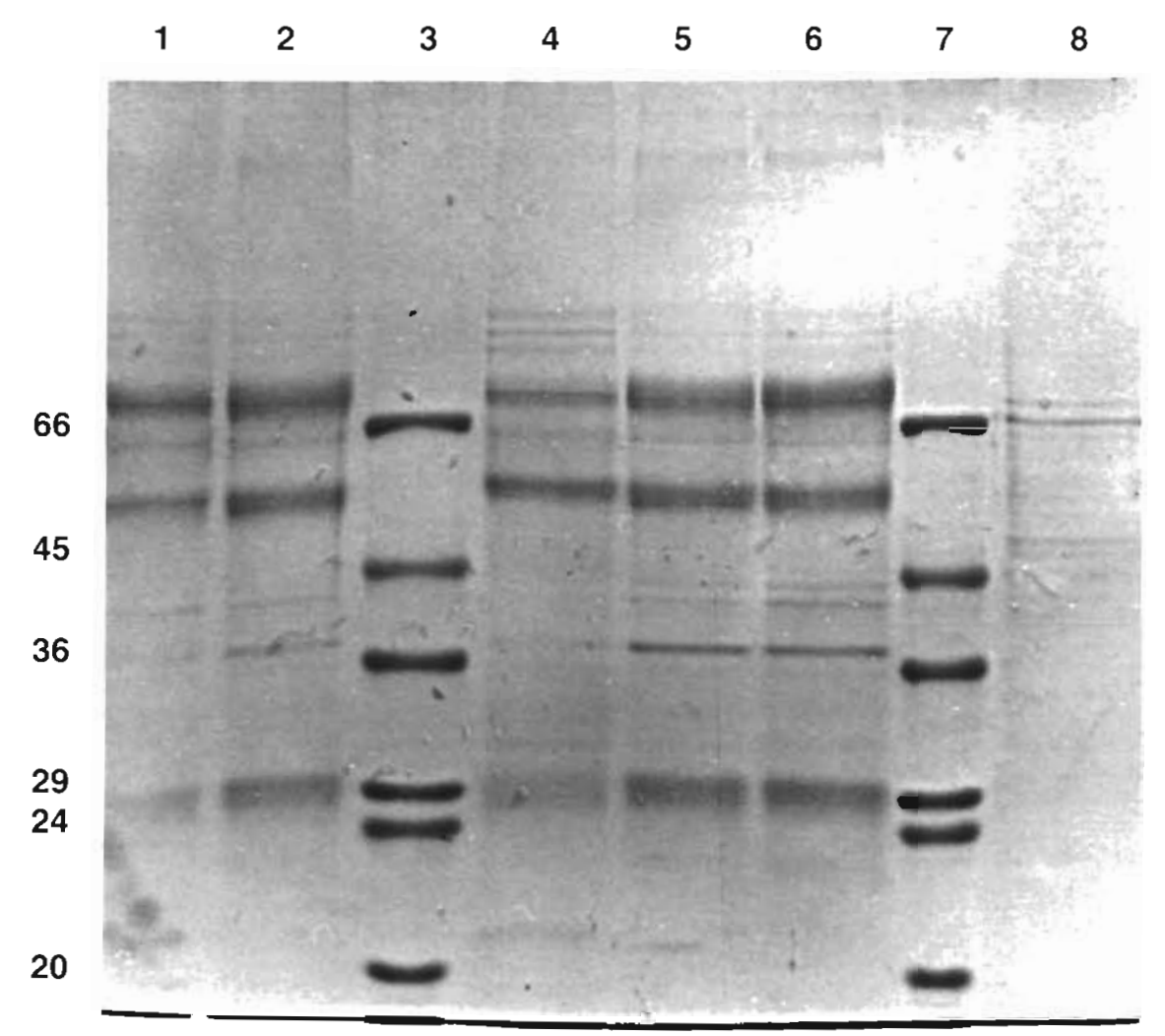

Fig. 1. SDS-polyacrylamide protein patterns of Erysipelothrix rhusiopathiae enzyme immunoassay antigens. Lane 1: Serotype 2; Lane 2: Serotype 5; Lane 3: molec. wt markers; Lane 4: Serotype 6; Lane 5: Serotype 21; Lane 6: Serotype partial 2; Lane 7: molec. wt markers; Lane 8: lithium chloride sodium acetate extract of Corynebacterium xerosis

newly captured in the Gulf of Mexico and bled immediately were sero-positive for antibodies to Erysipelothrix rhusiopathiae (cut-off point OD 0.263) compared with a group of wild dolphins living close to shore on the west coast of Florida, USA $(9 \%)(p<0.05)$.

Captive. The EIA values for captive dolphins and false killer whales are shown in Fig. 6. The 11 dolphins had been vaccinated 2 to 10 times over a 10 yr period with an Erysipelothrix rhusiopathiae bacterin. The EIA values in Fig. 6 are the lowest and highest values in each individual from many serum samples during the 10 yr period. Except as indicated, the lower EIA values for the false killer whales represent antibody levels at capture off the coast of Japan and the higher values 6 wk after vaccination at Ocean Park, Hong Kong Several dolphins were poor immune responders and 2 false killer whales had a drop in antibody level following vaccination.

Table 2. Tursiops truncatus and Pseudorca crassidens. EIA antibody values to Erysipelothrix rhusiopathiae in sera of 5 bottlenose dolphins and 1 false killer whale before and after adsorption with E. rhusiopathiae, Corynebacterium xerosis, and Listeria monocytogenes. All determinations made by enzyme immunoassay as described in 'Materials and Methods'

\begin{tabular}{|c|c|c|c|c|}
\hline \multirow[t]{2}{*}{ Sera source } & \multirow[t]{2}{*}{ Unadsorbed } & \multicolumn{3}{|c|}{ Serum adsorbed with (values are optical density) } \\
\hline & & E. rhusiopathiae & C. xerosis & L. monocytogenes \\
\hline \multicolumn{5}{|l|}{ Dolphins } \\
\hline 1 & 0.242 & 0.052 & 0.165 & 0.200 \\
\hline 2 & 0.518 & 0.112 & 0.316 & 0.348 \\
\hline 3 & 0.858 & 0.258 & 0.497 & 0.536 \\
\hline 4 & 0.707 & 0.248 & 0.530 & 0.566 \\
\hline 5 & 0.567 & 0.209 & 0.317 & 0.456 \\
\hline False killer whale & 0.530 & 0.090 & 0.437 & 0.499 \\
\hline
\end{tabular}



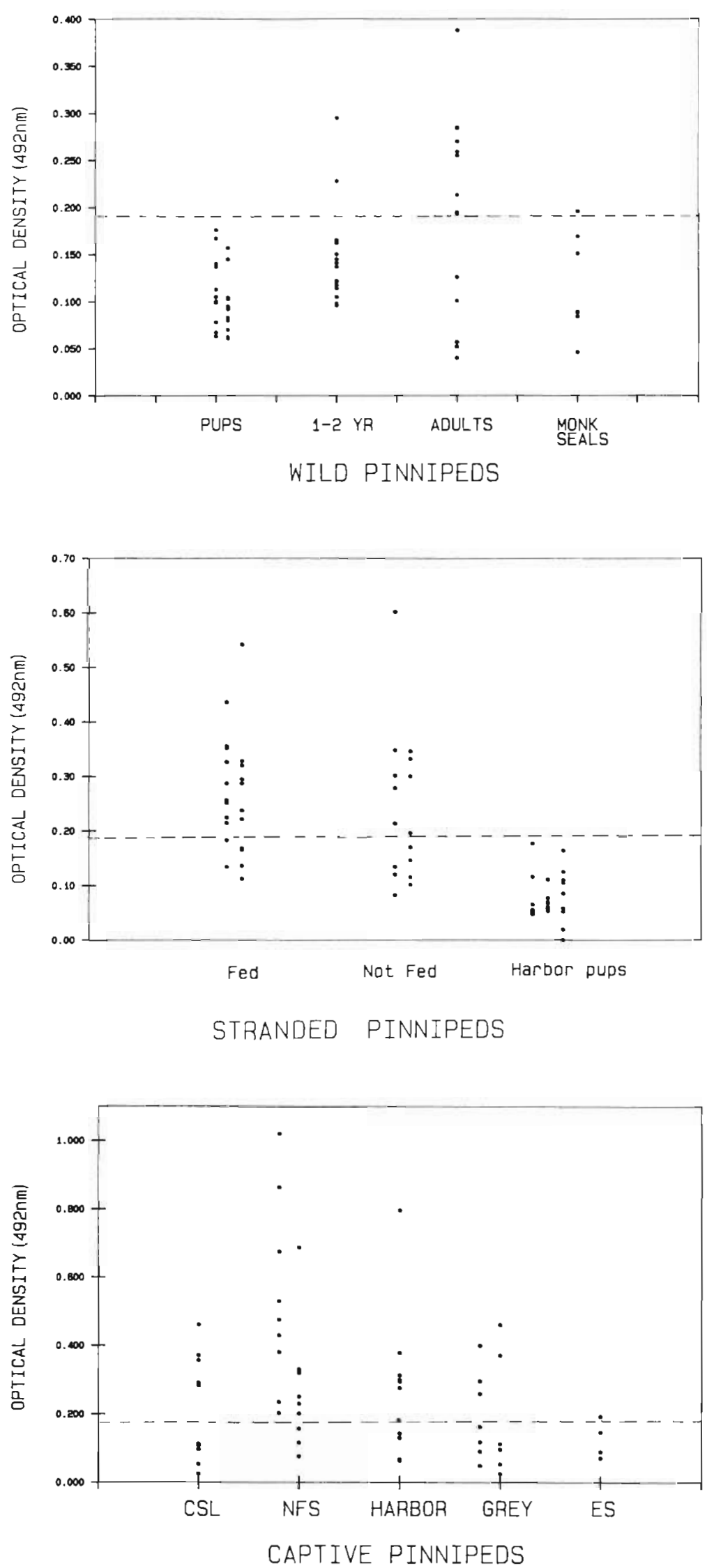

Fig. 2. Enzyme immunoassay antibody values to Erysipelothrix rhusiopathiae in wild NFS pups, 1- to 2-yr-old NFS, adult NFS, and Hawaiian monk seal pups. Dashed line: cut-off point (OD

0.187 ) between negative and positive sera

Fig. 3. Enzyme immunoassay antibody values to Erysipelothrix thusiopathiae in stranded adult CSL bled before and after being fed fish and stranded HS pups. Dashed line: as in Fig. 2

Fig. 4. Enzyme immunoassay antibody values to Erysipelothrix rhusiopathiae in captive CSL, NFS, HS, grey seals, and EL. Dashed line: as in Fig. 2 

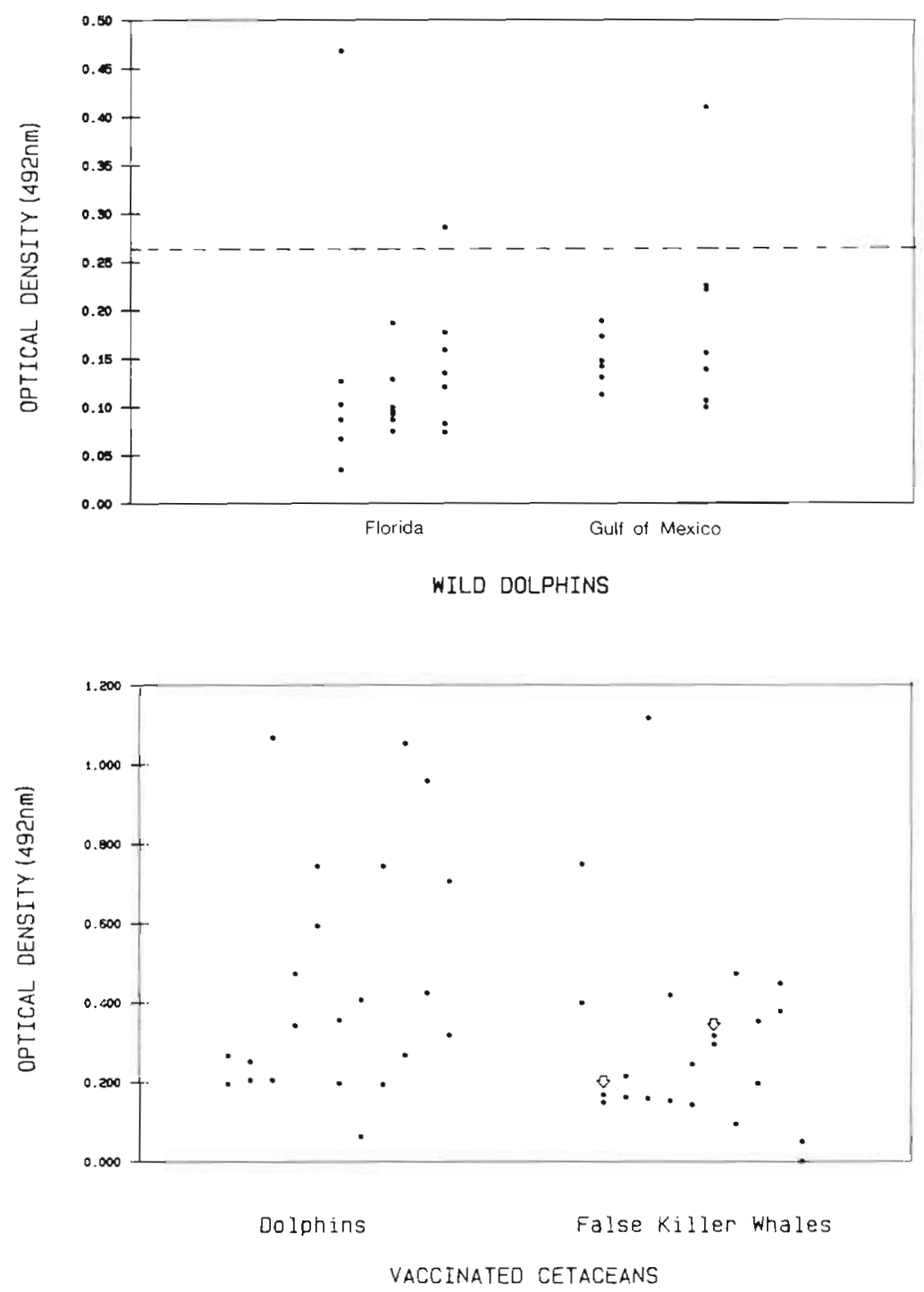

Fig. 5. Enzyme immunoassay antibody values to Erysipelothrix rhusiopathiae in wild dolphins newly captured in the Gulf of Mexico and a group in the waters off the west coast of Florida. Dasher line: rut-off point IOD 0.237 ) between negative and positive sera

\section{DISCUSSION}

In the present study a small percentage $(10 \%)$ of wild cetaceans had a sufficient challenge from Erysipelothrix rhusiopathiae in open marine waters to produce significant antibody levels (5 of 51 dolphins and 3 of 11 false killer whales; Fig. 5). A statistical comparison showed that the antibody response of these dolphins in the wild was significantly lower than either the highest or lowest antibody levels in captive dolphins $(p<0.05)$. However, 3 of 11 captive dolphins had negligible antibody titers after many vaccinations, as did 4 of 11 false killer whales after a single vaccination, although all of these animals were receiving their full quota of hand-fed fish. There were only 2 captive dolphins in the study which had been in captivity for $5 y \mathrm{r}$ and received no $E$. rhusiopathiae vaccination. Their EIA values from the last serum samples were
0.087 and 0.716 , respectively. The relationship between vaccination of cetaceans with different bacterins, immune response and level of protection will be the subject of a later report.

The wild pinnipeds (adults and 1- to 2-yr-old NFS and stranded adult CSL) consistently had higher antibody levels than wild cetaceans $(p<0.01)$. Neither of these 2 groups of animais ate fish handled by humans. Sera from the 1- to 2-yr-old NFS obtained from a colony on San Miguel Island, California, during a tagging expedition and the adult NFS were animals returning after a 2 yr pelagic cycle. None of the NFS pups had significant antibody levels to Erysipelothrix rhusiopathiae. Although we have no pre-history on the HS pups before stranding, the NFS pups were part of an extensive study in which it was observed that these animals did not absorb IgG from colostrum and were poor humoral antibody producers the first few days 
after birth (Cavagnola \& Vedros 1979). Thus, pups would not be expected to have significant antibody levels to any pathogen. Specific immunization of pregnant pinnipeds and the degree of passive immunity in the pups is now under study.

There are possible explanations for the erratic and low antibody levels noted in this report: (1) some animals are deficient in their immune response to antigens whether vaccinated or naturally exposed to a pathogen. This has been noticed in another study with Pseudomonas pseudomallei vaccine in dolphins (Vedros 1981); (2) the presence of Erysipelothrix rhusiopathiae in fish, whether in open waters or after being handled by humans, is sporadic and an individual animal may or may not receive a suitable antigenic challenge; and (3) the primary immune response to an oral challenge may be predominantly a rise in local IgA. To address these issues requires an expanded attempt to isolate other serotypes of E. rhusiopathiae from healthy pinnipeds and cetaceans, more frequent sampling of lots of fish for this pathogen, and evaluation of the immune response of individual animals being fed fish known to be contaminated with E. rhusiopathiae.

Acknowledgements. The authors thank Drs Randy Wells, Jay Sweeney, Derek Chow, Mobashir Solangi, and the staff of the California Marine Mammal Center for their generous gift of sera and assistance. This study was supported by grants from the Ocean Park Corp., Hong Kong, and the Mystic Aquarium, Mystic, Connecticut, USA.

\section{LITERATURE CITED}

Bruner, D. W., Gillespie, J. H. (1973). The Genus Erysipelothrix. In: Bruner, D. W., Gillespie, J. H. (eds.) Hagan's infectious diseases of domestic animals, 6 th edn. Cornell Univ. Press, Ithaca, p. 331-343
Cavagnola, R. Z., Vedros, N. A. (1979). Serum and colostrum antibody levels in northern fur seals (Callorhinus ursinus) Dev. compar. Immunol. 3: 139-146

Dubois, M., Gilles, K. A., Hamilton, J. K. (1956). Colorimetric method for determination of sugars and related substances. Analyt. Chem. 28: 350-356

Frasch, C. E. (1979). Noncapsular surface antigens of Neisseria meningitidis. In: Weinstein, L., Fields, B. N. (eds.) Seminars of infectious diseases, Vol. 2, Chap. 10. Stratton Intercontinental Med. Book Co., New York, p. 304-337

Klauder, J. V. (1938). Erysipeloid as an occupational disease. J. Am. med. Ass. 111: 1345-1348

Kramer, S. M., Jewell, N. P., Cremer, N. E. (1983). Discriminant analysis of data in enzyme immunoassay. J. immunol. Methods 60: 243-255

Lowry, O. H., Rosebrough, N. J., Farr, A. L., Randall, A. J. (1951). Protein measurements with the Folin phenol reagent. J. biol. Chem. 193: 265-275

Medway, W. (1980). Some bacterial and mycotic diseases of marine mammals. J. Am. vet. med. Ass. 177: 831-834

Mishell, B. B., Shiigi, S. M. (1980). Selected methods in cellular immunity. W. H. Freeman, San Francisco

Proctor, D. M., Richardson, I. M. (1954). A report of 235 cases of erysipeloid in Aberdeen. Br. J. ind. Med. 11: 75-179

Shewan, J. M. (1971). The microbiology of fish and fishery products. J. appl, Bacteriol. 341: 299-315

Suer, L. D., Vedros, N. A (1988). Erysipelothrix rhusiopathiae. I. Isolation and characterization from pinnipeds and bite/ abrasion wounds in humans. Dis. Aquat. Org. $5: 1-5$

Sweeney, J. (1978). Common diseases of pinnipeds. J. Am. vet. med. Ass. 165: 805-810

Vedros, N. A. (1981). The immune response of marine pinnipeds to various bacterial antigens. Proceedings of the 4 th biennial conference on the biology of marine mammals. (Abstracts.) San Francisco, p. 121

Voller, A., Bidwell, D., Bartlett, A. (1981). Enzyme linked immunosorbent assay. In: Rose, N. R., Friedman, H. (eds.) Manual of clinical immunology, 2nd edn, Chap. 45. Am. Soc. Microbiol., Washington, D. C., p. 359-371

Wood, R. L., Allen Packer, R. (1972). Isolation of Erysipelothrix rhusiopathiae from soil and manure of swine-raining premises. Am. J. vet. Res. 33: 1611-1620 